\title{
Biodigestão anaeróbia dos dejetos de cabritos Saanen alimentados com dietas com diferentes proporções volumoso e concentrado
}

\author{
Ana Carolina Amorim Orrico ${ }^{1}$, Marco Antonio Previdelli Orrico Junior ${ }^{2}$, Jorge de Lucas \\ Junior $^{3}$

\footnotetext{
1 Faculdade de Ciências Agrárias - Universidade Federal da Grande Dourados - MS.

2 Doutorando da Faculdade de Ciências Agrárias e Veterinárias - UNESP/Jaboticabal - SP.

${ }^{3}$ Faculdade de Ciências Agrárias e Veterinárias - UNESP/Jaboticabal - SP.
}

RESUMO - Avaliaram-se os efeitos da idade do animal e da proporção de volumoso nas dietas sobre a biodigestão anaeróbia dos dejetos de cabritos Saanen. Foram utilizadas as fezes produzidas por cabritos Saanen aos 90, 120 e 150 dias de idade e alimentados com dietas de três relações volumoso:concentrado (80:20, 60:40 e 40:60), representando as dietas 1, 2 e 3, respectivamente. Utilizaram-se biodigestores tipo batelada de bancada com capacidade para 12 litros de substrato em fermentação e 8\% de sólidos totais iniciais para determinação das produções e dos potenciais de produção de biogás e metano, da redução de sólidos voláteis e quantificação dos teores de minerais no afluente e efluente. As maiores reduções de sólidos voláteis foram observadas nos substratos preparados com as fezes de cabritos aos 150 dias alimentados com a dieta com relação volumoso:concentrado de 40:60. Os melhores rendimentos de substrato ou fezes foram obtidos com os dejetos dos cabritos de 120 e 150 dias de idade alimentados com a dieta com relação volumoso:concentrado 40:60. As maiores concentrações de minerais nos biodigestores foram observadas para as fezes de cabritos de 150 dias de idade alimentados com a dieta com relação volumoso:concentrado 40:60. A biodigestão anaeróbia é eficiente na remoção de coliformes nos dejetos de caprinos, proporcionando efluentes com no máximo $4,3 \times 10^{2}$ coliformes totais termotolerantes por grama de material.

Palavras-chave: biogás, caprino, metano, reciclagem

\section{Anaerobic biodigestion of manure of Saanen goats fed diets with different proportions of roughage and concentrate}

\begin{abstract}
It was evaluated the effects of age of the animal and of the proportion of dietary roughag on anaerobic biodigestion of the manure of Saanen kids. It was used the feces produced by Saanen kids at 90, 120 and 150 days of age and fed diets with three roughage:concentrate ratios (80:20, 60:40 and 40:60), representing diets 1,2 and 3, respectively. It was used batch digesters of bench with capacity for 12 liters of substratum in fermentation process and 8\% of initial total solids for determination of biogas and methane productions and production potentials, and reduction of volatile solids and quantification of mineral contents in affluent and effluent. The greatest volatile solid reductions were observed in substrata prepared with feces of goats at 150 days of age fed diets with roughage:concentrate ratio of 40:60. The best results of substratum or feces were obtained with manure of goats at 120 and 150 days of age fed diet with 40:60 roughage:concentrate ratio. The greatest concentrations of minerals in the biodigesters were observed for feces of goats at 150 days of age fed the diet 40:60 roughage:concentrate ratio. Anaerobic biodigestion is efficient in removing coliforms from goat manure, providing effluents with maximum of $4.3 \times 10^{2}$ of total and thermotolerant coliforms per gram of material.
\end{abstract}

Key Words: biogas, goat, methane, recycling

\section{Introdução}

O crescimento da caprinocultura brasileira tem se intensificado nos últimos anos, assim como tem ocorrido no cenário mundial, principalmente nos países em desenvolvimento. A expansão da atividade tem ocorrido pelo aumento do número de animais e pela melhoria dos índices produtivos e, em muitas situações, deixa de ocorrer em caráter de subsistência para assumir postura mais lucrativa e competitiva.

A geração de dejetos na criação dos animais faz parte do processo produtivo e pode representar importante fonte de renda (Silva et al., 2005; Santos et al., 2007). A reciclagem dos dejetos gerados na caprinocultura por meio da biodigestão anaeróbia possibilita, entre outras vantagens, a geração de biogás e biofertilizante, a redução do poder 
poluente dos dejetos e dos microrganismos indicadores de poluição fecal neles contidos, bem como a utilização da água residuária resultante da higienização das instalações, como parte do substrato de alimentação dos biodigestores.

Os dejetos de caprinos, quando submetidos à biodigestão anaeróbia, apresentam significativas produções de biogás (médias de 0,05 a 0,06 $\mathrm{m}^{3}$ de biogás. $\mathrm{kg}^{-1}$ de dejeto), superiores às obtidas quando se utilizam como substrato os dejetos provenientes de bovinos e ovinos. No entanto, independentemente da espécie, sabe-se que a alimentação dos animais tem efeito direto sobre as produções de biogás; Amorim et al. (2004) verificaram maiores rendimentos quando aumentaram a participação de concentrado na dieta dos animais. Outros fatores são responsáveis pelas alterações nas produções de biogás, como a idade e o estágio fisiológico dos animais, pois apresentam influência direta sobre o aproveitamento dos alimentos, que determinam a quantidade e qualidade dos dejetos excretados e influenciam nas quantidades de biogás produzidas durante o processo.

Orrico et al. (2007) efetuaram a biodigestão anaeróbia dos dejetos de cabras Saanen e observaram aumentos significativos, tanto na produção de biogás e metano como nos potenciais de produção dos mesmos gases, conforme reduziram a quantidade de volumoso na dieta. Os autores observaram aumento na eficiência de produção de 24,4 litros de biogás. $\mathrm{kg}^{-1}$ de sólidos totais adicionado quando a proporção de volumoso da dieta caiu de 80 para $40 \%$.

Considerando esses dados, realizou-se este trabalho com o objetivo de avaliar os efeitos das idades e da proporção de volumoso nas dietas sobre a biodigestão anaeróbia dos dejetos de cabritos Saanen.

\section{Material e Métodos}

O trabalho foi realizado no Laboratório de Digestão Anaeróbia do Departamento de Engenharia Rural utilizando-se os dejetos gerados no Setor de Caprinocultura do Departamento de Zootecnia, ambos pertencentes à Faculdade de Ciências Agrárias e Veterinárias, da Universidade Estadual Paulista/Unesp - Câmpus de Jaboticabal, cujas coordenadas geográficas são: $21^{\circ} 14^{\prime} 05^{\prime \prime}$ S; 48017’09" W e altitude média de 613,68 m.

A biodigestão anaeróbia foi desenvolvida com as fezes produzidas por cabritos Saanen aos 90, 120 e 150 dias de idade e alimentados com três dietas, com variação nas proporções entre volumoso e concentrado, por meio do abastecimento de biodigestores batelada. Durante a fase de engorda (dos 90 aos 150 dias de idade) os cabritos permaneceram em baias coletivas, separados por dietas, no entanto, para a colheita das fezes, foram alojados em gaiolas metabólicas individuais. Os animais foram alimentados com as dietas experimentais durante toda a fase de engorda, sendo que não foi necessário o período de adaptação às dietas para a colheita de fezes, considerando-se somente sete dias para a adaptação dos animais as gaiolas. Após os sete dias de adaptação foram realizadas as colheitas das fezes por cinco dias consecutivos, da seguinte forma: coletaram-se fezes dos animais dos 90 aos 95, dos 120 aos 125 e dos 150 aos 155 dias de idade.

As dietas empregadas na alimentação dos cabritos foram compostas de volumoso e concentrado nas seguintes proporções: $80 \%$ volumoso e $20 \%$ concentrado, $60 \%$ volumoso e $40 \%$ concentrado e $40 \%$ volumoso e $60 \%$ concentrado. $\mathrm{O}$ fornecimento da alimentação foi em cochos, à vontade, em duas refeições diárias, havendo à disposição dos animais água e sal mineral.

O volumoso utilizado foi o feno de capim-tifton 85 (Cynodon dactylon) e o concentrado foi composto de $53,8 \%$ de milho moído, $10,0 \%$ de soja grão, $15,0 \%$ de farelo de soja, 10,0\% de farelo de algodão, 5,0\% de farelo de trigo, 4,2\% de núcleo leite e 2,0\% de calcário calcítico. As dietas foram balanceadas para atender às exigências de ganho de 100 g/dia, segundo recomendações do NRC (1981).

Os biodigestores utilizados eram constituídos, basicamente, com três cilindros retos de PVC com diâmetros de 20, 25 e $30 \mathrm{~cm}$, acoplados sobre uma placa de PVC com 2,5 cm de espessura e podem ser caracterizados como biodigestores de bancada, com capacidade média de 12 litros de substrato, cada. Os cilindros de 20 e $30 \mathrm{~cm}$ encontravam-se inseridos um no interior do outro, de modo que o espaço entre a parede externa do cilindro interior e a parede interna do cilindro exterior comportasse um volume de água ("selo de água”), atingisse a profundidade de $50 \mathrm{~cm}$. O cilindro de diâmetro intermediário teve em uma das extremidades vedadas, conservando-se apenas uma abertura para descarga do biogás, e foi emborcado no selo de água, para propiciar condições anaeróbias e armazenar o gás produzido. Os biodigestores foram dispostos sobre uma bancada, em condições de temperatura ambiente, abrigados da luz solar e chuvas.

Os teores de sólidos totais (ST), sólidos voláteis (SV) e número mais provável de coliformes totais e termotolerantes das amostras coletadas durante a biodigestão anaeróbia foram determinados segundo metodologia descrita por APHA (2005). Os biodigestores foram avaliados por todo o período em que apresentaram produções de biogás. 
Os volumes de biogás produzidos diariamente, foram determinados medindo-se o deslocamento vertical dos gasômetros e multiplicando-se pela área da seção transversal interna dos gasômetros, ou seja, $0,0507 \mathrm{~m}^{2}$. Após cada leitura os gasômetros foram zerados utilizando-se o registro de descarga do biogás. A correção do volume de biogás para as condições de $1 \mathrm{~atm}$ e $20^{\circ} \mathrm{C}$ foi efetuada com base no trabalho de Caetano (1985).

O potencial de produção de biogás foi calculado utilizando-se os dados de produção diária e as quantidades de fezes in natura, de substrato, de sólidos totais, sólidos voláteis adicionados e sólidos totais e sólidos voláteis reduzidos durante o processo de biodigestão anaeróbia. Os valores foram expressos em $\mathrm{m}^{3}$ de biogás por kg de substrato, de dejetos ou de sólidos totais e voláteis. O potencial de produção de metano foi calculado com base nas produções de biogás e nos teores de metano contidos no biogás.

As análises da composição do biogás produzido foram realizadas semanalmente para determinação dos teores de metano $\left(\mathrm{CH}_{4}\right)$ e dióxido de carbono $\left(\mathrm{CO}_{2}\right)$, principalmente, em cromatógrafo de fase gasosa Finigan GC-2001, equipado com as colunas Porapack Q e Peneira Molecular, e detector de condutividade térmica.

As amostras coletadas durante o desenvolvimento dos ensaios de biodigestão anaeróbia foram pré-secas a $60^{\circ} \mathrm{C}$, em estufa de circulação forçada de ar, por 48 horas. Depois de secas, as amostras foram finamente moídas (peneira de $1 \mathrm{~mm}$ ), em moinho de facas, e utilizadas para a digestão da matéria orgânica e determinação dos sólidos totais (na temperatura de $105^{\circ} \mathrm{C}$ ) e dos sólidos voláteis. Para a digestão utilizou-se o digestor Digesdahl Hach, que promove a digestão total da matéria orgânica à base de ácido sulfúrico $\left(\mathrm{H}_{2} \mathrm{SO}_{4}\right)$ e peróxido de hidrogênio $\left(\mathrm{H}_{2} \mathrm{O}_{2}\right)$ a $50 \%$.

Com o extrato obtido da digestão sulfúrica foi possível efetuar a determinação dos teores de nitrogênio, fósforo, potássio, cálcio, magnésio, sódio, ferro, cobre, zinco e manganês, segundo Bataglia et al. (1983). O nitrogênio foi determinado conforme metodologia descrita por Silva \& Queiroz (2006). Os teores de fósforo foram determinados pelo método colorimétrico utilizando-se espectrofotômetro HACH, modelo DR-2000, citado em Silva \& Queiroz (2006). As concentrações de minerais foram determinadas em espectrofotômetro de absorção atômica modelo GBC 932 AA.

As determinações dos conteúdos das fibras em detergente neutro (FDN) e ácido (FDA), de celulose e lignina foram efetuadas conforme metodologias descritas por Silva \& Queiroz (2006).

Para comparar as dietas no ensaio de biodigestão anaeróbia dos dejetos gerados por cabritos durante fase de engorda, adotou-se delineamento inteiramente casualizado, em parcela subdividida, constando de três dietas (fator primário), três idades (fator secundário) e três repetições (animais), com comparação de médias pelo teste de Tukey a 5\% de probabilidade. Os resultados das variáveis obtidas foram submetidos à análise de variância utilizando o procedimento GLM(SAS, 2001).

\section{Resultados e Discussão}

As reduções médias de sólidos voláteis (Tabela 1) foram menores $(\mathrm{P}<0,05)$ quando se efetuou a biodigestão anaeróbia dos substratos produzidos com as fezes de animais alimentados com a dieta com relação volumoso:concentrado 80:20 (média de 28,34\%), em relação aos substratos produzidos com as fezes dos animais que consumiram aquela com $60 \%$ de volumoso e $40 \%$ de concentrado (média de $31,77 \%$ ), que foram inferiores às reduções obtidas nos substratos preparados com as fezes de animais alimentados com a $40 \%$ de volumoso e $60 \%$ de concentrado (média de 34,03\%).

Tabela 1 - Teores médios iniciais e finais de sólidos totais e voláteis e redução de sólidos voláteis observados durante o experimento

\begin{tabular}{|c|c|c|c|c|c|c|c|c|c|}
\hline \multirow{3}{*}{ Parâmetro } & \multicolumn{9}{|c|}{ Relação volumoso:concentrado da dieta } \\
\hline & \multicolumn{3}{|c|}{$80: 20$} & \multicolumn{3}{|c|}{$60: 40$} & \multicolumn{3}{|c|}{$40: 60$} \\
\hline & 90 dias & 120 dias & 150 dias & 90 dias & 120 dias & 150 dias & 90 dias & 120 dias & 150 dias \\
\hline Fezes (kg) & 2,7 & 2,71 & 3,03 & 2,4 & 2,67 & 2,39 & 2,3 & 2,67 & 3,21 \\
\hline Água (kg) & 9,3 & 9,29 & 8,97 & 9,6 & 9,33 & 9,61 & 9,7 & 9,33 & 8,79 \\
\hline Sólidos totais adicionados (\%) & 7,87 & 7,8 & 7,74 & 8,14 & 7,75 & 7,57 & 7,67 & 7,58 & 8,25 \\
\hline Sólidos totais adicionados (kg) & 0,94 & 0,94 & 0,93 & 0,96 & 0,93 & 0,91 & 0,92 & 0,91 & 0,99 \\
\hline Sólidos voláteis adicionados (\%) & 7,12 & 7,08 & 6,98 & 7,26 & 6,92 & 6,67 & 6,7 & 6,69 & 7,24 \\
\hline Sólidos voláteis adicionados (kg) & 0,85 & 0,85 & 0,84 & 0,85 & 0,83 & 0,8 & 0,8 & 0,8 & 0,87 \\
\hline Sólidos totais finais (\%) & 6,26 & 6,06 & 5,38 & 6,11 & 6,01 & 5,05 & 5,52 & 5,59 & 5,54 \\
\hline Sólidos totais finais (kg) & 0,75 & 0,73 & 0,65 & 0,72 & 0,72 & 0,61 & 0,66 & 0,67 & 0,66 \\
\hline Sólidos voláteis finais (\%) & 5,43 & 5,26 & 4,5 & 5,23 & 4,96 & 4,08 & 4,62 & 4,54 & 4,4 \\
\hline Sólidos voláteis finais (kg) & 0,65 & 0,63 & 0,54 & 0,61 & 0,6 & 0,49 & 0,55 & 0,54 & 0,53 \\
\hline Red SV (\%) & $23,8 \mathrm{Cc}$ & $25,7 \mathrm{Bc}$ & $35,5 \mathrm{Ac}$ & $28,0 \mathrm{Cb}$ & $28,4 \mathrm{Bb}$ & $38,8 \mathrm{Ab}$ & $31,0 \mathrm{Ca}$ & $32,2 \mathrm{Ba}$ & $39,2 \mathrm{Aa}$ \\
\hline
\end{tabular}

Na linha, letras maiúsculas comparam idade e letras minúsculas comparam dietas. Médias seguidas de letras distintas diferem (P<0,05) entre si pelo teste Tukey. 
Na avaliação do efeito da idade sobre a redução dos sólidos voláteis durante a biodigestão anaeróbia, as menores reduções $(\mathrm{P}<0,05)$ ocorreram em substratos preparados com as fezes de cabritos Saanen aos 90 dias de idade (média de 27,50\%) em relação àquele produzido com as fezes de animais aos 120 dias de idade (28,81\%), que apresentaram reduções inferiores às verificadas nos substratos provenientes das fezes de cabritos aos 150 dias de idade (37,84\%).

A redução no conteúdo de sólidos voláteis tendeu a ser menor nos animais com mais idade e conforme aumentou a participação de concentrado na alimentação. O fornecimento de alimento concentrado em maiores quantidades e o aumento na idade dos animais propiciaram a geração de substratos preparados com fezes de caprinas com os seguintes teores de FDN: 72,3; 66,6 e 58,7\% para cabritos Saanen com 90 dias de idade; 68,1; 62,4; e 56,0\% para cabritos Saanen com 120 dias de idade e 61,3; 57,1; e 49,5\% para cabritos Saanen com 150 dias de idade, alimentados com as dietas 1, 2 e 3, respectivamente. Esse mesmo comportamento foi observado para os conteúdos de FDA, celulose e lignina, e isso indica que o aumento da quantidade de alimento concentrado na composição das dietas e o crescimento dos animais proporcionaram fezes que provavelmente constituíram substratos mais assimiláveis durante a biodigestão anaeróbia, contribuindo inclusive com maiores quantidades de nutrientes disponíveis neste meio, favorecendo o desenvolvimento da população de microrganismos anaeróbios, o que pode ter facilitado a redução de material orgânico e a produção de biogás.

Os resultados indicam que houve aumento $(\mathrm{P}<0,05)$ na degradação da fração fibrosa (FDN, FDA e celulose) conforme aumentou a idade dos animais e quanto maiores quantidades de concentrado na dieta (Tabela 2). As reduções foram maiores à medida que os teores da fração fibrosa diminuíram nos substratos. Não houve degradação da lignina durante a biodigestão, uma vez que as quantidades desse componente mantiveram-se praticamente inalteradas. As reduções das frações FDN, FDA e celulose durante a biodigestão anaeróbia foram igualmente influenciadas pelas idades e dietas e foram proporcionais às reduções de sólidos voláteis.

As produções de biogás (Tabela 3) foram maiores $(\mathrm{P}<0,05)$ em substratos preparados com as fezes de cabritos Saanen alimentados com a dieta com relação volumoso:concentrado 40:60 (média de 0,2445 $\mathrm{m}^{3}$ ) em comparação às produções observadas nos substratos das fezes de animais que receberam a dieta com relação 60:40 (média de $0,2187 \mathrm{~m}^{3}$ ), que, por sua vez, foram superiores aos produzidos com fezes de animais que consumiram a dieta 80:20 (média de $0,1843 \mathrm{~m}^{3}$ ). A idade dos animais afetou as produções de biogás, visto que os maiores valores foram observados nos substratos preparados com as fezes de cabritos Saanen aos 150 dias de idade (média de 0,2314 m³) em relação às produções obtidas em substratos produzidos com as fezes de cabritos aos 120 dias de idade (média de $0,2286 \mathrm{~m}^{3}$ ), que foram superiores às verificadas em substratos originados das fezes de cabritos aos 90 dias de idade (média de $0,1874 \mathrm{~m}^{3}$ ).

Assim como observado para produção de biogás (Tabela 3), as quantidades de metano nos substratos foram maiores nas fezes de animais de maiores idades e alimentados com maior proporção de concentrado, e isso comprova a importância da biodigestão anaeróbia das fezes dos animais mais velhos, visto que as quantidades de metano geradas na fermentação desses resíduos são aproximadamente

Tabela 2 - Quantidades de fibra em detergente neutro (FDN), fibra em detergente ácido (FDA), celulose e lignina e respectivas reduções durante a biodigestão anaeróbia

\begin{tabular}{|c|c|c|c|c|c|c|c|c|c|c|}
\hline \multirow[t]{3}{*}{ Fração } & & \multicolumn{9}{|c|}{ Relação volumoso:concentrado da dieta (em \%) } \\
\hline & & $80: 20$ & $60: 40$ & $40: 60$ & $80: 20$ & $60: 40$ & $40: 60$ & $80: 20$ & $60: 40$ & $40: 60$ \\
\hline & & \multicolumn{3}{|c|}{90 dias de idade } & \multicolumn{3}{|c|}{120 dias de idade } & \multicolumn{3}{|c|}{150 dias de idade } \\
\hline \multirow{3}{*}{$\begin{array}{l}\text { Fibra em detergente } \\
\text { neutro }(\mathrm{kg})\end{array}$} & Afluente & 0,68 & 0,64 & 0,54 & 0,64 & 0,58 & 0,51 & 0,57 & 0,52 & 0,49 \\
\hline & Efluente & 0,53 & 0,45 & 0,36 & 0,47 & 0,41 & 0,35 & 0,38 & 0,32 & 0,30 \\
\hline & Red (\%) & $22,06 \mathrm{Cc}$ & $29,82 \mathrm{Cb}$ & $33,09 \mathrm{Ca}$ & $26,56 \mathrm{Bc}$ & $28,71 \mathrm{Bb}$ & $30,55 B \mathrm{a}$ & $33,60 \mathrm{Ac}$ & $38,19 \mathrm{Ab}$ & $38,59 \mathrm{Aa}$ \\
\hline \multirow{3}{*}{$\begin{array}{l}\text { Fibra em detergente } \\
\text { ácido (kg) }\end{array}$} & Afluente & 0,38 & 0,35 & 0,30 & 0,37 & 0,34 & 0,31 & 0,33 & 0,31 & 0,26 \\
\hline & Efluente & 0,31 & 0,26 & 0,22 & 0,29 & 0,25 & 0,22 & 0,23 & 0,20 & 0,17 \\
\hline & Red (\%) & $18,42 \mathrm{Cc}$ & $24,43 \mathrm{Cb}$ & $26,67 \mathrm{Ca}$ & $21,62 \mathrm{Bc}$ & $26,47 \mathrm{Bb}$ & $29,03 \mathrm{Ba}$ & 30,09Ac & $35,86 \mathrm{Ab}$ & $36,34 \mathrm{Aa}$ \\
\hline \multirow[t]{3}{*}{ Celulose (kg) } & Afluente & 0,25 & 0,21 & 0,19 & 0,22 & 0,21 & 0,19 & 0,22 & 0,19 & 0,16 \\
\hline & Efluente & 0,19 & 0,15 & 0,13 & 0,16 & 0,15 & 0,13 & 0,15 & 0,12 & 0,10 \\
\hline & Red (\%) & $24,00 \mathrm{Cc}$ & $27,14 \mathrm{Cb}$ & $29,98 \mathrm{Ca}$ & $26,38 \mathrm{Bc}$ & $26,80 \mathrm{Bb}$ & $31,65 \mathrm{Ba}$ & $33,90 \mathrm{Ac}$ & $36,09 \mathrm{Ab}$ & $37,60 \mathrm{Aa}$ \\
\hline \multirow[t]{3}{*}{ Lignina (kg) } & Afluente & 0,13 & 0,14 & 0,11 & 0,15 & 0,13 & 0,12 & 0,11 & 0,13 & 0,10 \\
\hline & Efluente & 0,13 & 0,14 & 0,11 & 0,15 & 0,13 & 0,12 & 0,11 & 0,13 & 0,10 \\
\hline & Red (\%) & 1,69 Aa & $0,62 \mathrm{Aa}$ & 2,09Aa & $0,58 \mathrm{Aa}$ & $-0,54 \mathrm{Aa}$ & $0,76 \mathrm{Aa}$ & $-2,57 \mathrm{Aa}$ & $-3,99 \mathrm{Aa}$ & $2,79 \mathrm{Aa}$ \\
\hline
\end{tabular}


Tabela 3 - Produção e potenciais de produção de biogás e metano dos dejetos de cabritos Saanen

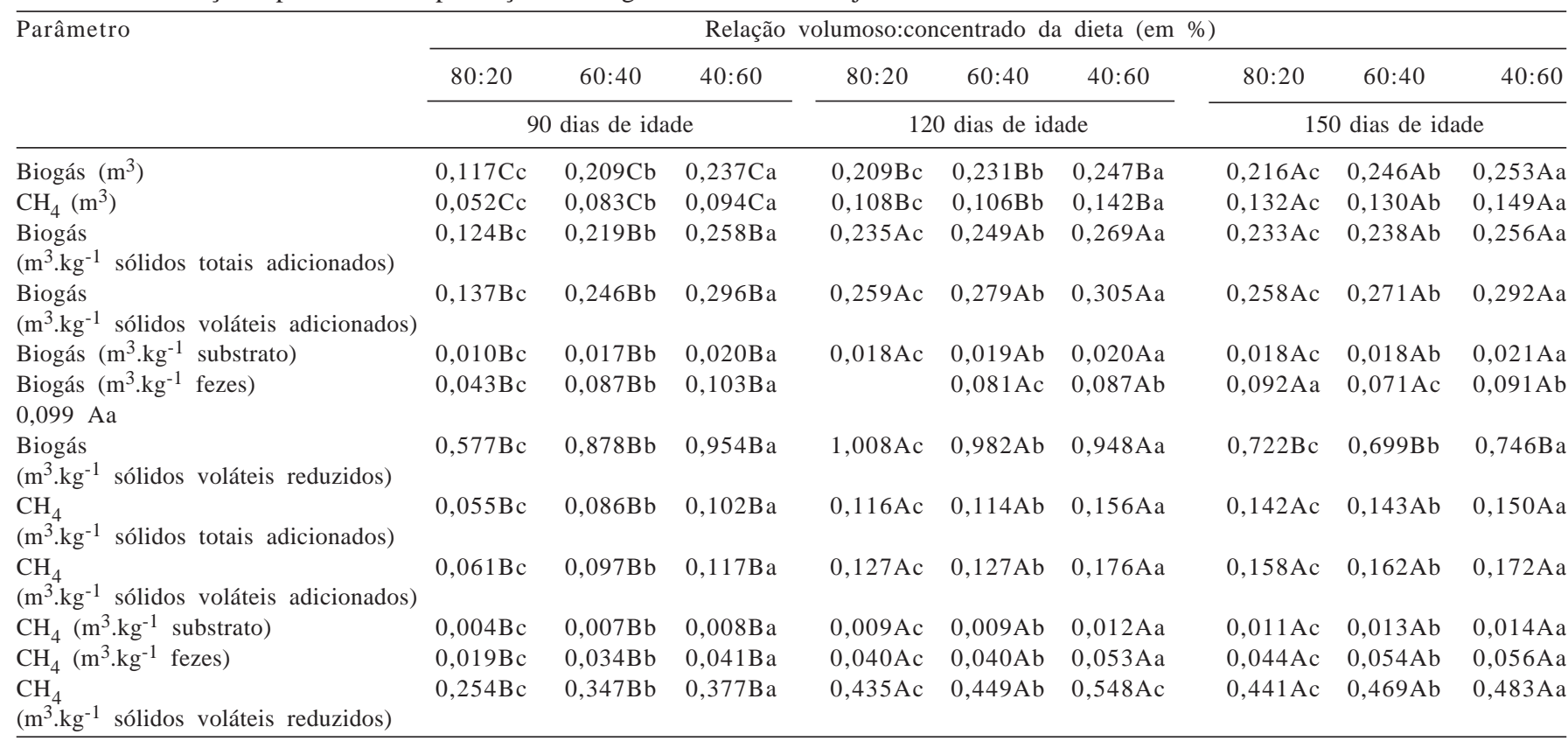

Na linha, letras maiúsculas comparam idade e letras minúsculas comparam dietas. Médias seguidas de letras distintas diferem (P<0,05) entre si pelo teste Tukey. $\mathrm{CH}_{4}=$ gás metano.

$300 \%$ mais elevadas que as de caprinos aos 90 dias de idade alimentados com a dieta contendo $80 \%$ volumoso e $20 \%$ concentrado (0,052 $\mathrm{m}^{3}$ de metano) em relação aos substratos preparados com as fezes de cabritos aos 150 dias de idade e recebendo a dieta contendo $40 \%$ volumoso e $60 \%$ concentrado $\left(0,149 \mathrm{~m}^{3}\right.$ de metano).

Os potenciais de produção de biogás (Tabela 3) por kg de sólidos totais e sólidos voláteis adicionados, kg de substrato e kg de fezes, sofreram o mesmo efeito das idades e dietas, pois os valores foram maiores $(\mathrm{P}<0,05)$ no caso dos substratos preparados com as fezes de cabritos Saanen aos 120 e 150 dias de idade, em relação àqueles produzidos com as fezes de cabritos aos 90 dias de idade. Também foram maiores $(P<0,05)$ quando se utilizaram as fezes dos animais alimentados com as dietas contendo 60 e $40 \%$ de volumoso em relação às fezes de animais que receberam a dieta com $80 \%$ de volumoso. Esse comportamento reforça os efeitos benéficos da idade e da maior qualidade das dietas, mencionadas anteriormente, sobre a composição dos dejetos e a biodigestão anaeróbia.

Não houve efeito $(\mathrm{P}>0,05)$ das dietas nem da idade dos cabritos sobre a redução dos números mais prováveis de coliformes totais e termotolerantes durante a biodigestão anaeróbia das fezes (Tabela 4). Os números de coliformes nos efluentes não ultrapassaram os limites recomendados para os rios de classe 2, destinados à aquicultura ou à recreação de contato primário (CONAMA, 2005), preconizados em no máximo 1.000 coliformes termotolerantes por $100 \mathrm{~mL}$ de efluente. Esses efluentes, segundo disposição do CONAMA (2005), poderão ser empregados na irrigação de hortaliças, plantas frutíferas e de parques, jardins, campos de esporte e lazer, com os quais a população pode ter contato direto. Novamente, ressalta-se a importância da biodigestão anaeróbia na remoção de microrganismos

Tabela 4 - Número mais provável médio de coliformes totais e termotolerantes nos afluentes e efluentes dos biodigestores

\begin{tabular}{|c|c|c|c|c|c|c|c|c|c|}
\hline & \multicolumn{9}{|c|}{ Relação volumoso:concentrado na dieta (em \%) } \\
\hline & $80: 20$ & $60: 40$ & $40: 60$ & $80: 20$ & $60: 40$ & $40: 60$ & $80: 20$ & $60: 40$ & $40: 60$ \\
\hline & \multicolumn{3}{|c|}{90 dias de idade } & \multicolumn{3}{|c|}{120 dias de idade } & \multicolumn{3}{|c|}{150 dias de idade } \\
\hline \multirow{4}{*}{$\begin{array}{l}\text { Aflentes } \\
\text { Efluentes }\end{array}$} & & & & \multicolumn{3}{|c|}{ Coliformes totais } & & & \\
\hline & $2,4 \times 10^{9}$ & $2,4 \times 10^{9}$ & $1,7 \times 10^{9}$ & $4,6 \times 10^{10}$ & $4,6 \times 10^{10}$ & $2,4 \times 10^{8}$ & $4,6 \times 10^{9}$ & $2,4 \times 10^{9}$ & $7,5 \times 10^{8}$ \\
\hline & $<3$ & $4,3 \times 10$ & $4,3 \times 10^{2}$ & $4,3 \times 10$ & $<3$ & $<3$ & $1,2 \times 10$ & $2,3 \times 10$ & $<3$ \\
\hline & \multicolumn{9}{|c|}{ Coliformes termotolerantes } \\
\hline Afluentes & $2,4 \times 10^{9}$ & $2,4 \times 10^{9}$ & $1,7 \times 10^{9}$ & $4,6 \times 10^{10}$ & $4,6 \times 10^{10}$ & $2,4 \times 10^{8}$ & $4,6 \times 10^{9}$ & $2,4 \times 10^{9}$ & $7,5 \times 10^{8}$ \\
\hline Efluentes & $<3$ & $4,3 \times 10$ & $4,3 \times 10^{2}$ & $4,3 \times 10$ & $<3$ & $<3$ & $1,2 \times 10$ & $2,3 \times 10$ & $<3$ \\
\hline
\end{tabular}

Na linha, letras maiúsculas comparam idade e letras minúsculas comparam dietas. Médias seguidas de letras distintas diferem (P<0,05) entre si pelo teste de Tukey. 
indicadores de poluição fecal, assegurando a qualidade do biofertilizante, principalmente quando os reatores são operados com maiores tempos de retenção hidráulica (TRH).

Resultados semelhantes foram encontrados por Coté et al. (2006), que observaram eficiência de 97,94 a 100\% nas reduções de coliformes termotolerantes e totais em sistemas de biodigestão anaeróbia, mesmo em condições de baixa temperatura $\left(20^{\circ} \mathrm{C}\right)$. Segundo esses autores, a eficiência na redução dos microrganismos patogênicos está associada à temperatura de fermentação e ao tempo de retenção hidráulica utilizado, pois, quanto maiores forem os seus valores, mais eficiente será a redução de patógenos. Na literatura existem várias pesquisas (Amorim et al., 2004; Mentz et al., 2004; Amaral et al., 2004), que comprovam a eficiência do processo de biodigestão anaeróbia na redução de diversas espécies de organismos patogênicos.

\section{Conclusões}

Animais mais velhos alimentados com dietas com maior proporção de concentrado produzem dejetos com maior teor de nutrientes, o que aumenta a importância do tratamento desses resíduos.

\section{Referências}

AMARAL, C.M.C.; AMARAL, L.A.; LUCAS JÚNIOR, J. et al. Biodigestão anaeróbia de dejetos de bovinos leiteiros submetidos a diferentes tempos de retenção hidráulica. Ciência Rural, v.34, n.6, p.1897-1902, 2004.

AMERICAN PUBLIC HEALTH ASSOCIATION; AMERICAN WATER WORKS ASSOCIATION; WATER ENVIRONMENT FEDERATION - APHA/AWWA/WEF. Standard methods for examination of water and wastewater. 21.ed. American Washington, D.C.: Water Works Association, 2005. 1368p.

AMORIM, A.C.; LUCAS JUNIOR, J.; RESENDE, K.T. Utilização de dejetos produzidos por caprinos como substrato para os processos de compostagem e vermicompostagem. Revista Brasileira de Engenharia Agrícola, v.24, n.1, p.16-24, 2004. BATAGLiA, O.G. Métodos de análises químicas de plantas 1.ed. Campinas: Instituto Agronômico, 1983. 48p.

CAETANO, L. Proposição de um sistema modificado para quantificação de biogás. 1985. 75f. Dissertação (Mestrado em Energia na Agricultura) - Faculdade de Ciências Agronômicas/ Universidade Estadual Paulista, Botucatu.

CONSELHO NACIONAL DO MEIO AMBIENTE - CONAMA. Padrões de qualidade para os parâmetros monitorados na rede de monitormento CONAMA 20/86. Disponível em: $<$ http://www.cetesb.sp.gov.br/QualidadeRios/anexo2>. Acesso em: $1 / 4 / 2005$.

CÔTE, C.; MASSE, D.I.; QUESSY, S. Reduction of indicator and pathogenic microorganisms by psychrophilic anaerobic digestion in swine slurries. Bioresource Technology, v.97, n.1, p.686-691, 2006.

MENTZ, M.B.; WIEST, J.M.; GONCALVES, P.C. Viabilidade de ovos de Fasciola hepatica de bovinos em sistema de biodigestão anaeróbia. Arquivo Brasileiro de Medicina Veterinária e Zootecnia, v.56, n.4, p.550-553, 2004.

NATIONAL RESEARCH COUNCIL - NRC. Nutrient requeriments of goat. 6.ed. Washington: National Academy Press, 1985. 99p.

ORRICO, A.C.A.; LUCAS JÚNIOR, J.; ORRICO JÚNIOR, M.A.P. Caracterização e biodigestão anaeróbia dos dejetos de caprinos. Engenharia Agrícola, v.27, n.3, p.639-647, 2007.

SANTOS, T.M.B.; LUCAS JUNIOR, J.; SILVA, F.M. Avaliação do desempenho de um aquecedor para aves adaptado para utilizar biogás como combustível. Engenharia Agrícola, v.27, n.3, p.658-664, 2007.

SILVA, D.J.; QUEIROZ, A.C. Análise de alimentos: métodos químicos e biológicos. 3.ed. Viçosa, MG: Editora Universitária, 2006. 166p.

SILVA, F.M.; LUCAS JUNIOR, J.; BENINCASA, M. et al. Desempenho de um aquecedor de água a biogás. Engenharia Agrícola, v.25, n.3, p.608-614, 2005.

STATISTICAL ANALYSIS SYSTEM - SAS. SAS/STAT user's guide. Version 6, 4.ed. Cary: SAS Institute, 1990. 891p. 